\title{
Study on the Effects of Different Vegetation Restoration Models on Soil Remediation
}

\author{
Yijie Dong ${ }^{1}$, Yuanyuan Luo ${ }^{1 *}$, Jinbiao Li $^{1}$, Shanqiao Deng ${ }^{1}$, Zhiyang Zheng ${ }^{1}$ \\ ${ }^{1}$ (NO.290 Research Institute of Nuclear Industry, Shaoguan 512029, China)
}

\begin{abstract}
In order to improve the restoration effect of soils in mining wasteland, based on site investigations for the mining wasteland, five different vegetation restoration models are used for soil restoration, and study on effect mechanism of different vegetation restoration models on physical and chemical properties as well as activity of enzyme in soil are conducted, providing a solid theoretical basis for guiding the subsequent management of the soil in the mining area.
\end{abstract}

\section{Introduction}

Coal will keep it dominant position in China's energy structure for a long period of time in the future. Although massive coal mining has contributed to the growth of the national economy, it has caused destruction of ecological balance at the location of coal mine, for example, the prominent contradictions between resources, land and the environment therefrom have caused serious damages to the ecological environment in the coal mine, and even serious degradation of the soil at the site [1]. However, the current methods used for restoration of the ecological environment are relatively single in mining areas, showing poor effect.

Generally speaking, the first priority for ecological environment restoration in mining areas is to restore the surface vegetation as only with vegetation restoration can the overall structure and fertility of the soil be ensured, and in this way, microorganisms and animals in the area can be he restored. The paper will study the effects of different vegetations on the soil restoration in the mining area and make optimization of the plan based on the investigation and study of the mining wasteland. The details are described as follows:

\section{Site investigation of mining wasteland}

Coal mining in the mining area has caused the surrounding area show a landform that is largely different from the current ecological background, and the vegetation types and characteristics also present obvious changes due to the effect of different landform characteristics. As time goes by, the vegetation in the coal mine area changed, for example, major vegetation becomes simple shrub and grass communities after 5 years of abandonment; and changes to relatively complete arbor-shrub-grass communities after 25 years of abandonment. It is proposed to use classical sampling methods to study the community characteristics of the mining area at different recovery stages in order to fully grasp the vegetation conditions of the mining area under study. In terms of basis investigation on the vegetation in the mining area, it may include types and numbers of tree species in the arbor layer, the types and number of tree species in the shrub layer, as well as the types and types of plants in the herb layer. From site investigation, the following conclusions are concluded:

(1) According to statistics, there are 97 kinds of vegetation in the mining wasteland, which is relatively less as compared with the domestic vegetation types;

(2) The vegetation types in the mining area include Leguminosae, Gramineae, Compositae, Rosaceae, Euphorbiaceae, Willow Family, Liaceae, Pinaceae, Liliaceae, Lamiaceae, Verbenaceae, Cyperaceae, etc. To sum up, the mining wasteland is dominated by a single family with regard to vegetation;

(3) The vegetation covered by the mining area is mainly distributed across the world, pantropical zone and northern temperate zone.

For refined analysis, it is necessary to classify the mining wasteland into five types, and and count the vegetation characteristics of each type of wasteland, and finally obtain the diversity characteristics of different types of wastelands in the mining area, as shown in Table 1 :

Table 1 Margalef index of different types of wastelands in mining area

\begin{tabular}{|c|c|c|c|}
\hline $\begin{array}{c}\text { Wasteland } \\
\text { category }\end{array}$ & $\begin{array}{c}\text { Arbor } \\
\text { layer }\end{array}$ & $\begin{array}{c}\text { Shrub } \\
\text { layer }\end{array}$ & $\begin{array}{c}\text { Herb } \\
\text { layer }\end{array}$ \\
\hline Category I & 0 & 0 & 1.52 \\
\hline Category II & 0 & 0.39 & 1.74 \\
\hline Category III & 0 & 1.17 & 1.82 \\
\hline Category IV & 0.91 & 1.50 & 2.14 \\
\hline Category V & 0.92 & 1.55 & 2.43 \\
\hline
\end{tabular}

*Unyuan Luo: 5161135@qq.com 
It can be learned from the investigation on the vegetation types of mining wasteland: to quickly know the effect of vegetation restoration in wasteland, tropical pioneer plants musted selected as the main vegetation, but allocated numbers of tropical plants must properly determined according to the actual situation. Besides, pioneer plants of nature; in addition, native plants with temperate nature should be considered as the key plants for vegetation restoration in the wasteland, as well as proper mixing of tropical pioneer plants and temperate native plants [2].

\section{Study on the effect of different vegetation on soil restoration}

This part will mainly study the effects of different vegetation restoration models on the physical, chemical, and biochemical properties of soil in wasteland. Based on site condition of the wasteland, it is advised to plant the plant communities for disaster prevention, the plant communities for nitrogen fixation and barren resistance, the plant communities for composite ecological agriculture and forestry, the plant communities for health care, and the plant communities for ecological landscape of the mining area.

Among them, the plant communities for disaster prevention are mainly have high adaptability, including roses, Ailanthus altissima, cypress, and paper mulberry in the upper layer; yellow thorn rose, oleander, wattle, etc. in the middle layer; and sweet clover, Pharbitis purpurea (L.) Voisgt and horseweed herb in the lower layer. The above plant community with disaster prevention function not only enriches the local vegetation collocation, but also prevents loss of water and soil erosion.

The plant community for nitrogen fixation and barren resistance can improve soil fertility, favorable for restoration of vegetation and soil restoration in the mining area. It comprises Robinia pseudoacacia and populus euramericana in the upper layer; Amorpha fruticosa, and Lespedeza, Ladedge with large leaves and dalbergia hupeana in the middle layer; Chinese trumpet creeper, alfalfa and wild soybeans in the lower layer.

The plant community for compound ecological agriculture and forestry is dominated by fruit trees with strong stress resistance, which can not only have better soil restoration effects, but also bring in certain economic benefits. It includes Robinia pseudoacacia, jujube, hawthorn and Pyrus pyrifolia in the upper layer; elaeagnus pungens, Cotoneaster silvestrii, sea-buckthorn in the middle layer; Astragalus sinicus and Melilotus suavcolen in the lower layer [3].

Plant community for health care is dominated by medicinal plants with strong stress resistance, which can restore vegetation in wasteland and also bring in certain economic benefits. It includes Ligustrum lucidum, Ginkgo biloba L., and Phellodendri Chinensis Cortex in the upper layer; Forsythia suspensa, Lonicera japonica, Lonicera confusa, Gardenia stenophylla in the middle layer, etc.; lophatherum gracile, Glabrous Greenbrier Rhizome, Polygonum multiflorum in the lower layer.
In terms of the plant community for ecological beauty in the mining area, those suitable for the survival in the wasteland are selected on the basis of environmental design and plant adaptability analysis. It includes Koelreuteria integrifoliola Merr, amorpha fruticosa, Salix matsudana, Cedrus deodara in the upper layer; Fruit of Chinese Holly, Lonicera maacki, Lagerstroemia indica, and Jasminum nudiflorum in the middle layer; Gossypium aridum and Euonymus fortunei in the lower layer.

\subsection{Impact of different vegetation restoration models on soil physical properties}

To study the physical properties of soil, cutting ring method is used to determine the soil bulk density, water holding capacity, and porosity of the sample, with the aid of the measurement instruments including shakers, centrifugal machine, analytical balances, and spectrophotometers. The data determined by the above method and instruments are then analyzed by SPSS16.0 software to obtain the differences in soil physical properties, and also the correlation coefficient of Person.

It is planned to plant communities including different categories of plants are planted on the wasteland, and check the restoration of soil under different types of plant communities five years by analyzing change characteristics of parameters such as soil bulk density, total porosity, capillary porosity, and non-capillary porosity and water content.

(1) Changes of soil bulk density in different vegetation restoration models

Soil bulk density is an indicator that reflects the physical characteristics of the soil, mainly indicating the soil's ability to hold surface water. From the determination of bulk density of soil at different depths in the above five vegetation restoration models, it can be concluded that the the plant community for ecological beauty in the mining area has the largest soil bulk density, followed by the plant community for nitrogen fixation and barren resistance, and the soil bulk density of plant community for health care is the worst.

In general, all the above five vegetation restoration models can improve the soil bulk density in the area, but the improvement effect varies largely. Best improvements in soil bulk density of the area is achieved by planting the plant communities for ecological beauty.

(2) Changes of soil porosity in different vegetation restoration models

The total soil porosity, as an important indicator of soil physical characteristics, mainly reflects the permeability of the soil in the area. Through study, we can learn that five different vegetation restoration models have good effect in improving the porosity (permeability) of the soil in the area, and among them the plant community for the beautiful landscape in the mining area shows the best improvement effect. Soil porosity is divided into capillary porosity (with soil diameter less than $0.1 \mathrm{~mm}$ ) and non-capillary porosity (with soil diameter greater than $0.1 \mathrm{~mm}$ ), and it is learned from analysis that: for soil capillary porosity, it is possible to 
achieve more improvements if plant communities for disaster prevention are planted; for non-capillary porosity, better improvements can be made with the plant community for beautiful landscape of the mining area [4].

(3) Changes of soil water content in different vegetation restoration models

Soil water content is a key indicator of soil physical characteristics, which will directly promote or inhibit the soil recovery rate. Five years of experiments show that, the above five vegetation restoration models all can increase the soil water content in the area. The plant communities for nitrogen fixation and barren resistance exhibits the best effect in terms of increasing the soil water content in the area.

\subsection{Impact of different vegetation restoration models on soil chemical properties}

The chemical properties of soil involve determination of the content of various micro elements and the $\mathrm{pH}$ value in the soil. Micro elements including organic $\mathrm{C}$, total $\mathrm{N}$, total $\mathrm{P}$, total $\mathrm{L}$, quick-acting $\mathrm{N}$, quick-acting $\mathrm{P}$, and quick-acting $\mathrm{K}$ are determined by proper test methods; the $\mathrm{pH}$ value in the soil is measured by a $\mathrm{pH}$ meter. The test is targeted at the chemical properties in $0-20 \mathrm{~cm}$ topsoil layer, the $20-40 \mathrm{~cm}$ soil layer and the $40-60 \mathrm{~cm}$ soil layer under different vegetation restoration models. The data determined by the above method and instruments are then analyzed by SPSS16.0 software to obtain the differences in soil physical properties, and also the correlation coefficient of Person.

(1) Changes of soil organic C content in different vegetation restoration models

The content of organic $\mathrm{C}$ in the soil largely reflects the fertility and the fertility maintenance level of soil, and sufficient content of organic $\mathrm{C}$ can also improve the water holding capacity, permeability and water permeability of the soil. According to the analysis on the obtained data, in the $0-20 \mathrm{~cm}$ topsoil layer, the plant communities for nitrogen fixation and barren resistance and the plant communities for disaster prevention have high organic $\mathrm{C}$ content; in the $20-40 \mathrm{~cm}$ soil layer, the $\mathrm{C}$ contents in the soil in different vegetation restoration models are basically equivalent; in the $40-60 \mathrm{~cm}$ soil layer, the soil with the plant communities for nitrogen fixation and barren resistance shows highest organic $\mathrm{C}$ content.

(2) Changes of soil total $\mathrm{N}$ content in different vegetation restoration models

$\mathrm{N}$ is a key element to boost plant growth, which can directly reflect the overall level of nutrients in the soil area. According to the analysis on the obtained data, under the impact of the same vegetation restoration model, the total $\mathrm{N}$ content in the topsoil layer is higher than the total $\mathrm{N}$ content in the $20-40 \mathrm{~cm}$ soil layer and higher than the total $\mathrm{N}$ content in the $40-60 \mathrm{~cm}$ soil layer. In a soil layer of the same thickness, the plant community for nitrogen fixation and barren resistance has the highest total $\mathrm{N}$ content, i.e. the highest nutrient content.
(3) Changes of soil total $\mathrm{P}$ content in different vegetation restoration models

$\mathrm{P}$ is also a key element for plant production, which mainly determines metabolism and production development of plant. From the analysis on the obtained data, it can be concluded that various vegetation restoration models can significantly increase the total $\mathrm{P}$ content in each soil layer of the soil. For the $0-20 \mathrm{~cm}$ topsoil layer, the plant community for disaster prevention has the highest total $\mathrm{P}$ content; for the $20-40 \mathrm{~cm}$ and $40-60 \mathrm{~cm}$ soil layers, the surrounding communities for nitrogen fixation and barren resistance have the highest total $\mathrm{P}$ content.

(4) Changes of soil total $\mathrm{K}$ content in different vegetation restoration models

Total $\mathrm{K}$ content in soil reflects the storage capacity of $\mathrm{K}$ in the studied soil. It can be learned from the statistical analysis of the measured data that the effect of different vegetation restoration models on the total $\mathrm{K}$ content in the soil is mainly seen in the $0-20 \mathrm{~cm}$ topsoil layer. For specific, in the $0-20 \mathrm{~cm}$ topsoil layer, the total $\mathrm{K}$ content of the main plant community with total nitrogen and barren resistance is highest, while the total $\mathrm{K}$ content of the plant community for health care is the lowest, with an increment of $0.25 \mathrm{~g} / \mathrm{kg}$; and in the $20-40 \mathrm{~cm}$ superlayer, the total $\mathrm{K}$ content of the main plant community with total nitrogen and barren resistance is the highest, but with an increment of only $0.10 \mathrm{~g} / \mathrm{kg}$.

Therefore, for the total $\mathrm{K}$ content in the soil, the synergy of the total $\mathrm{K}$ content of the main plant community with total nitrogen tolerance is the most obvious.

(5) Changes of $\mathrm{PH}$ value of soil in different vegetation restoration models

PH value in the soil affects the activity of microorganisms and enzymes in the soil, which will affect the absorption and transformation efficiency of nutrient elements in the soil by plants. In addition, $\mathrm{PH}$ value of soil is also an important factor affecting its fertility. Statistical analysis of the measured data shows: the same vegetation restoration mode has different impacts on the $\mathrm{PH}$ value of soil in different depths; for specific, the impact on the $\mathrm{PH}$ of the $0-20 \mathrm{~cm}$ topsoil layer is the largest, followed by the $20-40 \mathrm{~cm}$ soil layer; when the soil depth is more than $40 \mathrm{~cm}$, the vegetation restoration model can have no impact on its $\mathrm{PH}$ value. For the $0-20 \mathrm{~cm}$ topsoil layer of and the $20-40 \mathrm{~cm}$ soil layer, the plant community for ecological beauty in the mining area has the most significant impact on the $\mathrm{PH}$ value [5].

\subsection{Impact of different vegetation restoration models on soil biochemical properties}

The biochemical properties of soil mainly refer to the activity of enzymes contained in the soil. The enzymes in the soil and the microorganisms contained may have different impacts on the growth of vegetation. Hence, this section will focus on the effects of different vegetation restoration models on the change characteristics of dehydrogenase, urease, and catalase activities in the soil. 
It is proposed to use specific determination methods and steps for different enzymes, and analyze the differences in soil physical properties with SPSS16.0 software to obtain the correlation coefficient of Person.

(1) Changes of dehydrogenase activity in different vegetation restoration models

Dehydrogenase in the soil mainly functions to promote the nitrogen cycle reaction, with ammonia and carbon dioxide as the resulting products. To put it simply, dehydrogenase mainly provides sufficient nitrogen source for higher plants in the relevant soil. Regarding the activity of dehydrogenase, the impacts of the same vegetation restoration model on the respective dehydrogenase activity in different soil layers are relatively identical, for specific, in the $0-20 \mathrm{~cm}$ topsoil layer, $20-40 \mathrm{~cm}, 40-60 \mathrm{~cm}$ soil layers, plant communities for nitrogen fixation and barren resistance have the highest dehydrogenase activity; while the plant communities for health care have the lowest dehydrogenase activity.

(2) Changes of urease activity in different vegetation restoration models

Urease in the soil mainly functions to promote the conversion of urea in the soil into ammonia and carbon dioxide, and ultimately provide sufficient nitrogen source for higher plants in the soil. With regard to urease, the activity of urease in soils at different depths under the same vegetation restoration model becomes worse as the depth increases; while in the soil at the same depth, the plant community for nitrogen fixation and barren resistance has the highest urease activity; while the plant community for health care has the lowest urease activity.

(3) Changes of catalase activity in different vegetation restoration models

Catalase mainly functions to promote the conversion of hydrogen peroxide in the soil into water and oxygen, which thereby solves the problem of excessive hydrogen peroxide content in the soil affecting the plant growth. With regard to catalase, the activity of catalase in the soil at different depths under the same vegetation restoration model becomes worse as the depth increases; while in the soil at the same depth, the plant communityfor nitrogen fixation and barren resistance has the highest catalase activity; while the plant communities for health care has the lowest urease activity.

\section{Conclusion}

Although coal mining has contributed to the increased revenues of the national economy, it has caused severe destruction of the local ecological environment, especially pollution of the soil in the area. In order to solve the problem of soil pollution caused by coal mining, the paper has conducted a study on the effect mechanism of different vegetation restoration models on the soil remediation effect, and the following conclusions are obtained:

(1) Application of different vegetation restoration models in the soil of mining wasteland can improve the physical properties of the soil. Specifically speaking, it can effectively reduce the bulk density of the soil, improve the water holding capacity of the soil and expand the soil porosity. In general, the plant community for nitrogen fixation and barren resistance presents the most obvious effect on improving the physical properties of soil, and the plant community for health care has the least effect.

(2) Different vegetation restoration models can all improve the chemical properties of the soil when they are used for the soil in the wasteland. In general, the plant community for nitrogen fixation and barren resistance presents the most obvious effect on improving the chemical properties of soil, and the plant community for health care has the least effect.

(3) Different vegetation restoration models can all improve the activity of enzyme in the soil when they are used for the soil in the wasteland. In general, the plant community for nitrogen fixation and barren resistance presents the most obvious effect on improving the activity of enzyme soil, which is followed by the plant community with disaster prevention function.

\section{References:}

1. Pan Zhiqiang, Zhang Shuqin, Ren Dajun, et al. Effects of direct application of urban sewage sludge on soil remediation in mining areas [J]. Environmental Engineering, 2019, v.37; No.257(11): 186+192-196.

2. Wu Zongshu, Ai Jiaoyan, Li Xiuhua, et al. Sampling optimization of soil remediation in mining area based on intelligent algorithm[J]. Environmental Engineering Journal, 2016.

3. Bian Zhengfu, Lei Shaogang, Jin Dan, et al. Several basic issues of land restoration in mining areas[J]. Journal of China Coal Society, 2018, 043(001): 190-197.

4. Xie Zhengmiao, Yu Tianming, Jiang Juntao. Preliminary study on bentonite remediation of contaminated soil in mining areas $[\mathrm{J}]$. Bulletin of Science and Technology, 2009, 25(1):109-113.

5. Liu Xiuyu, Fang Dejian, Wu Langpeng, et al. Study on the remediation plant of heavy metal contaminated soil in lead-zinc mining area and its pulping and papermaking performance[J]. Transactions of China Pulp and Paper, 2018, 33(03):17-22. 